\title{
Retraction Note: Marine biological characteristics and environmental legal policy optimization based on heterogeneous computing environment
}

\author{
Ming Jiang ${ }^{1}$
}

Published online: 30 November 2021

(c) Saudi Society for Geosciences 2021

Retraction Note: Arabian Journal of Geosciences (2021) 14: 1534

https://doi.org/10.1007/s12517-021-07949-9

The Editor-in-Chief and the Publisher have retracted this article because the content of this article is nonsensical. The peer review process was not carried out in accordance with the Publisher's peer review policy. The author has not responded to correspondence regarding this retraction.

The original article can be found online at https://doi.org/10.1007/ s12517-021-07949-9

Ming Jiang

jm05170701@163.com

1 Law School, Changsha University of Science \& Technology,

Changsha 410114, Hunan, China 